\title{
INTRODUCING INTELLIGENCE AND AUTONOMY INTO INDUSTRIAL ROBOTS TO ADDRESS OPERATIONS INTO DANGEROUS AREA
}

\author{
Agostino G. BRUZZONE ${ }^{1}$, Marina MASSEI ${ }^{1}$, Riccardo DI MATTEO ${ }^{2}$, Libor \\ KUTEJ $^{3}$ \\ ${ }^{1}$ Simulation Team, DIME, University of Genoa \{agostino, massei\} @itim. unige. it \\ ${ }^{2}$ Simulation Team, SIM4Future \{dimatteo@simulationteam.com \\ ${ }^{3}$ University of Defence in Brno \{libor.kutej@unob.cz\}
}

\begin{abstract}
The paper addresses the issue to use new generation robotic systems inside industrial facilities in order to complete operations in dangerous area. The new robotic systems are currently adopting the autonomous approach already in use in military sector; however, in this context the intensity of operations and the necessity to interact with high productivity systems introduce different challenges. Despite the problems, it is evident that this approach could provide very interesting improvements in terms of safety for humans especially in relations to dangerous area. For instance in confined spaces, Oil \& Gas or Hot Metal Industry these new autonomous systems could reduce the number of injures and casualties. In addition, these systems could increase the operation efficiency in this complex frameworks as well as the possibility to carry out inspections systematically; in this sense, this could result in improving the overall reliability, productivity and safety of the whole Industrial Plant. Therefore, it is important to consider that these systems could be used to address also security aspects such as access control, however they could result vulnerable to new threats such as the cyber ones and need to be properly designed in terms of single entities, algorithms, infrastructure and architecture. From this point of view, it is evident that Modeling and Simulation represent the main approach to design properly these new systems. In this paper, the authors present the use of autonomous systems introducing advanced capabilities supported by Artificial Intelligence to deal with complex operations in dangerous industrial frameworks. The proposed examples in oil and gas and hot metal industry confirm the potential of these systems and demonstrate as simulation supports their introduction in terms of engineering, testing, installation, ramp up and training.
\end{abstract}

Keywords: Artificial Intelligence, Autonomous Systems, Safety, Industrial Plants, Security, Modeling and Simulation 


\section{Introduction}

With the term UxVs (Unmanned Vehicles) are indicate all the remote vehicles operating in different environment (aerial, ground, surface, underwater) with different levels of autonomy (piloted remotely, fully autonomy). These new technologies are one of the focuses of Industry 4.0 due their characteristics that make them well adapt to substitute human for many danger operations (Bruzzone et al. 2017).

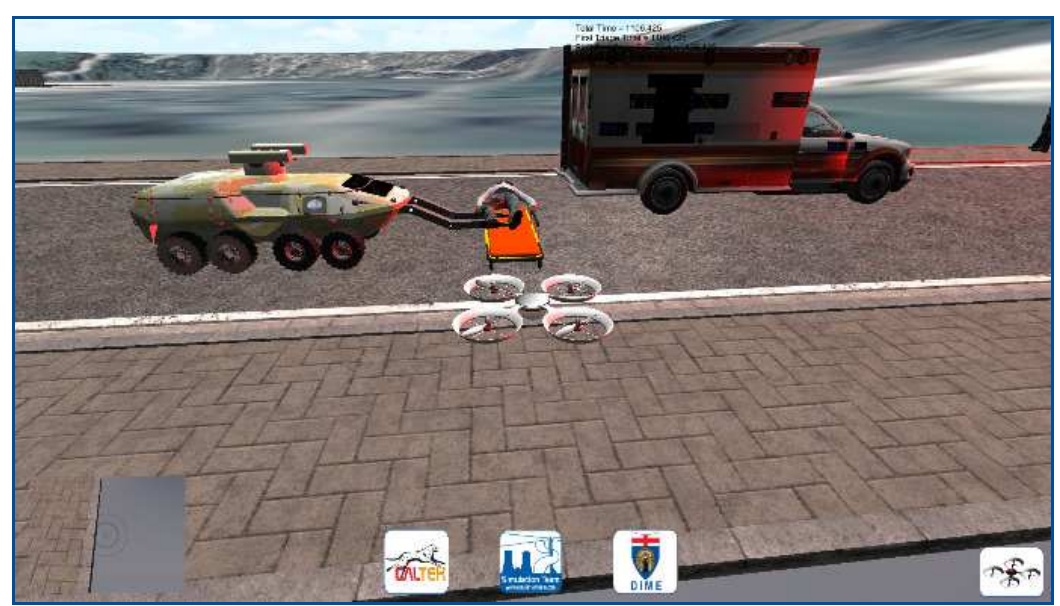

Figure 1 -Simulator operating Autonomous Systems for emergencies in Industrial Plants

Indeed, due their agility, speed and expandable nature UxVs can reach easily place dangerous and/ or difficult to access increasing safety in industrial plants. For these reasons, Autonomous Systems popularity is increasing exponentially in the last period and researchers are studying possible uses in different application field (Salvini 2017). In addition, the authority and agencies of security and prevention have manifested their interest in UxVs studying possible uses of them in many applications (Clarke et al. 2014; Di Donato 2017); in Italy for example, the Department of Technological Innovation (DIT) is promoting the diffusion of Autonomous System in dangerous operations substituting humans. In this way the want increase safety in industrial plants reducing the exposure of people to potential dangerous environments for addressing difficult tasks (Spanu et al. 2016).

By the way, the introduction of UxVs in industrial Plants, if from one side increase the safety, from other side introduce new problems and risks that require to be investigated. Simulation can give great efforts in the investigation of these possible problems finding them soon and searching their solution. 


\section{Application cases}

In this paper are proposed different scenario where is investigate the potential use of different Autonomous Systems in Industrial Plants for increasing safety and security. These cases show various opportunities, risks and challenges derives from the uses of these technologies in the industrial sector and underline the need of creating training programs and procedures for the use UxVs. Many different kinds of UxV operate over multiple domains: land (UGV, Unmanned Ground Vehicles), air (UAV, unmanned Aerial Vehicles), surface (USV, Unmanned Surface Vehicles) and underwater (AUV, Autonomous Underwater Vehicles).

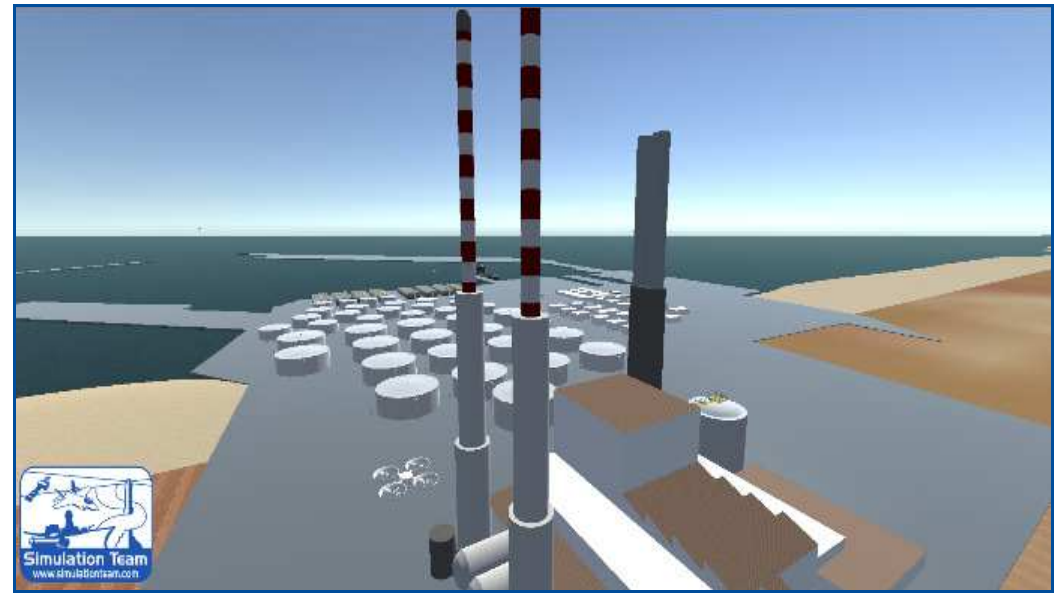

Figure 2 - UAV overview within Critical Infrastructure Protection Simulator

\section{$3 \quad$ UxV \& Safety}

The use of UxVs in industrial plants is studied with the main goal of increasing safety; the versatility, the operational cost and the expandable nature of autonomous systems makes them perfect in substitute the human in those tasks that are particular difficult and/or in dangerous environment (Apvrille et al.2015; Merwaday \& Guvenc 2015; Altawy et al. 2016). Unfortunately, the contexts of these operations are very complex and so results very complex the implementations of UxVs too. In order to investigate $\mathrm{UxV}$ problems, M\&S (Modelling and Simulation) results the methodology most promising by its ability to well reproduce complex scenario (Bruzzone et al. 2016a).

The projects about using $\mathrm{UxV}$ for Industry and major Agencies along last years are several and one of the most active entity in this field is the Simulation Team of the University of Genoa that has acquires a large experience in autonomous systems. The Simulation Team is an International Network working on simulation technologies and 
is studying the use of autonomous systems in different application from several year, including the collaborative multi domain cases (Bruzzone et al. 2014, 2016b).

In Italy INAIL-DIT is studying how to integrate Autonomous and Remote Pilot Systems in the actual Industrial plants paying particular attention to all new safety aspects that the use of them create in these scenarios. However, the safety is only one of the multiple topics that will need to take in account before the effective use of $\mathrm{UxVs}$ in working area; for example, could be useful study the development of new advanced equipment, or study new materials suitable for drones for protect them or people working in the same area (Valavanis et al. 2014; Sanchez-Lopez et al. 2016). It is also very important that regulation and tecnologies standard follow all the innovative processes within Industry 4.0 including autonomous systems and remote pilot systems (Kehoe et al.2015). If, for example, we analyze a typical example of the possible use of UxVs as could be the use of a remote piloting system, we immediately understand the complexity of the context. First, a person drives the robotic system and in the area of the $\mathrm{UxV}$ mission, there may be present human personnel working that introduce issues about safety.

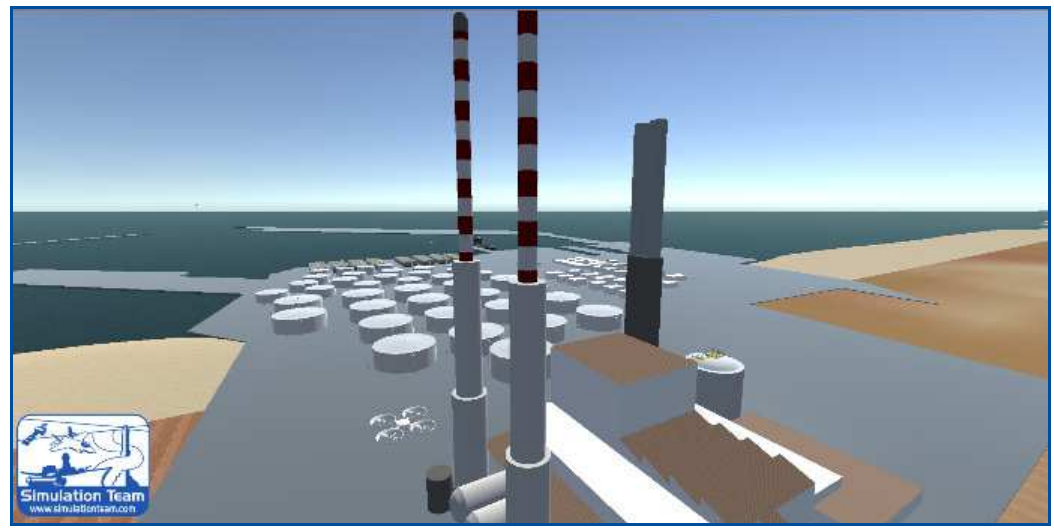

Figure 3 -Protection of Port Framework by USV and other Autonomous Systems

This implies the necessity of a training for the staff as well as the drafting of rules and regulations on the use of this technology to protect the safety of workers and for the transposition of the applicable product. From this context, it also emerges that the authorities involved are different; in fact, in addition to the European commission, state departments, ministries and public administrations are also involved. In the case of the example in Italy, they would be involved: the Ministry of Labour and Social Policies, the Health and Safety of Workers, the Ministry of Labour Infrastructure and Transport, for Aviation Security or Navigation and the National Agency for Civil Aviation. The UxVs can be used in many application fields that different each other in terms of environment (eg open spaces or closed) and actions to be performed (eg monitoring, valve closures, taking samples) depending on both the type of drone that its equipment. For better understand how many and different can be the possible usages of $\mathrm{UxVs}$, in the following are presented a set of possible fields of application. 
The UxVs could easily replace the humans in these tasks reducing risks and increasing the safety of workers no longer forced to expose themselves daily to certain dangers. Another possible field of application is the use of drones in confined spaces where there may be dispersion of hazardous materials: in these environments, in fact, accidents are still frequent maybe due to an incorrect analysis of risks (Spillane et al. 2012; Nano et al.2013; Leão et al. 2015). The drones could access these areas with adequate sensors before human and warn of the presence of these possible substances (Valavanis et al. 2014, Floreano \& Wood 2015). Obviously, before of using drone in these scenarios an accurate analysis of the boundary conditions should be performed in order to use $\mathrm{UxVs}$ in a safety mode avoiding possible risks of accidents (presence of liquid, electromagnetic fields, vapors etc.). The UxV could also be used to make environmental surveys with high resolution cameras or to monitor the infrastructures with the most modern sensors such as GPR (Ground Penetrating Radar) which allow to check the conditions of underground infrastructures (water leaks, cracks etc.). Furthermore, UxVs have the capability to operate in swarm exchanging instantaneously each other data increasing drastically the performance on monitoring plants (Kovacevic et 11. 2016).

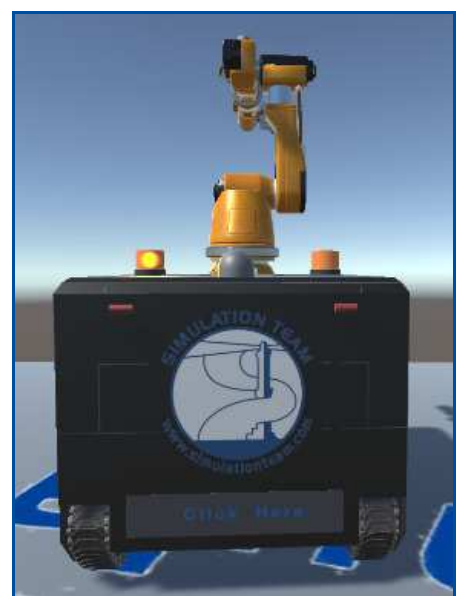

Figure 4-UGV with arm to perform task in Industrial Plant under development by Simulation Team

In this field, there are many studies because it is considered one of the most promising direction in the future use of autonomous systems (Burkle et al. 2011).

Data acquired from swarm could be exchange also with a master control unit an advise instantaneously a human if is approaching a dangerous areas; in this way it is supposed to developed a smart guiding support that provide automatic corrective actions on vehicles, such as find an alternative way or reduce the speed (Kim et al. 2015). Another possible use of UxVs results to be the plant monitoring as well as evaluating flue gas emissions in different areas or by different machines (Gardi et al. 2016). The benefits from this application arise because often machinery, for construction 
restrictions, can't mount directly on themselves the sensors for monitoring their emissions and the environment near them doesn't permit to add fixed sensor (Ishiki et al. 2014). For these reasons, UxVs could be very good candidate to make these monitoring operations adding them the sensors needed for getting the measurements and, in some case, also tailored arm for reach the best position where take them. Another possible usage of $\mathrm{UxVs}$ that has been studied is in the field of irrigations machines in herbaceous and tree crops (Pulina et al. 2016). In this cases, UxVs can be used to evaluate drift of fertilizers equipping UAV with special high definition (HD) camera and recording the machineries from different point of view (Pizzarella 2014). The tracked drift motion, thanks to an a red powdered food mixed to the liquid, can be replicated on aerial photo through GIS Support. In this way making more test with different weather condition it can be possible analyse the different drift situations. UxVs can make aerial reconnaissance for having direct view of the situation in some critical scenarios helping in this way in the management of emergency relief activities (Doherty et al. 2007). Indeed, the Image captured from AUV/ROV, are usable to understands the more critical area or which area is safe and which no etc. Therefore, the application fields are many and different and can involves different kind of drones. The cases presented are only some of the possible employments of UxVs and all of them should be analysed fine in order to finding the critical issues and procedures to be adopted. $M \& S$ is a powerful and useful instrument for address these problems (Bruzzone et al. 2014).

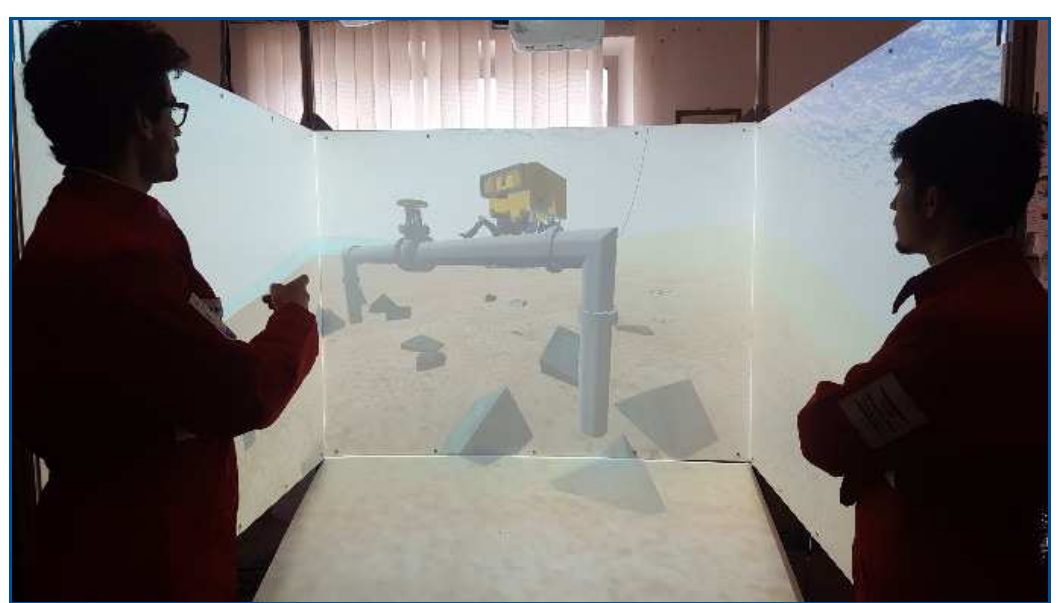

Figure 5 - Man on the Loop: Supervising Underwater Oil Operations within the SPIDER special CAVE 


\section{Safety in Off-Shore Operations}

The authors developed different cases related to oil \& gas industries operations on off-shore facilities where the combined use of AUV, ROV (Remoted Operated Vehicles), USV and UAV were devoted to conduct operations and improve safety and security (Bruzzone et al.2017). Among these R\&D (Research and Development ) projects it could be mentioned the case of SO2UCI (Simulation for Off-Shore, OnShore \& Underwater Critical Infrastructure), CRIPEM (CRitical Infrastructure Protection in Extended Maritime framework) and Megacity for Wind Farms at sea (Bruzzone et al.2014, 2017); similar projects addressed also industrial plants such as power plants and desalination facilities in on-shore installation as in T-Rex (Threat network simulation for REactive eXperience) and IDRASS (Immersive Disaster Relief and Autonomous System Simulation) to improve safety and security (Bruzzone et al.2016b, 2016c). In all these cases it was fundamental to develop collaboration capability among different $\mathrm{UxV}$ on different domains (Bruzzone et al.2013); these aspects required to develop Artificial Intelligence (AI) modules for the coordination as well as for scenario awareness used also to assess situations and priorities; in this sense the authors adopted a combined use of data fusion among fuzzy logic allocation matrices defining fuzzy rules, intelligent agents (IA) controlling the platforms and artificial neural networks (ANN) for correlating complex aspects (Bruzzone 2017). The use of SPIDER (Simulation Practical Immersive Dynamic Environment for Reengineering) solution developed and applied by the author to supervise multiple UxV collaborating is an example of how new generation CAVE (Cave Automatic Virtual Environment) could be useful in this field (Bruzzone et al.2016a, 2017).

\section{UGV inside a Plant}

Another interesting case is related to the following example on the utilization of $\mathrm{M} \& S$ as virtual prototyping approach to develop an innovative UGV in industrial plants; this was sometime combined with use of small UAV for indoor operations as in IDRASS cases or applied on oil \& gas facilities as well as hot metal industry (Bruzzone et al.2017).

Hereafter the focus is just on ground operations that due to the complexity of plant environment require to introduce AI effective module for task execution and movements. The aim of this research is to evaluate the possibility to use mobile robots for performing dangerous operations inside a plant and thus replacing human activities. In facts in this case the UGV in this way reduce exposition and frequency of human presence in dangerous areas, especially during most risky operations, allowing to increase the safety; therefore in addition to prevent accident to humans, such flexible robotic system could also represent an useful resource to carry out operations during crises for assessing damages, carrying out safe procedures and even look for people blocked by the accident. 
In facts this requires to develop special and complex capabilities in robotic systems such as the possibility to complete a complex mission in articulated environments considering the characteristics of the plant processes as well as the high density in such facilities of equipment, , cables, machines and components that could introduce difficulties in moving and operating. It should be considered also that in case of accidents, many of these facilities result immediately pretty dangerous for humans and requires to carry out specific tasks respect industrial processes (e.g. shut down machines, close valves and apply safety procedures) to verify the possibility of accident escalation, addressing a proper emergency planning and actions for injured personnel such as triage. Due to these reasons the use of autonomous systems to act as "first responders" assessing the situation and to support relief operations are very promising especially if integrated with legacy systems already available on the field.

The research addressed the following topics:

- Goals and Expectations for a new industrial UGV

- Definition of Hypotheses and Constraints related to Operations, Environment and Boundary Conditions

- Survey on Existing Technologies, Autonomous System Configurations, Platforms

- Review of Examples \& Experiences, carried out using Autonomous Systems, interesting for the case study

- Identification of platforms potentially usable

- UGV Operator Requirements and Regulations

- Definition of Tailored Solutions for the Case Study

- Feasibility, General Performance, Flexibility, Extensibility to other operations/plants/markets

- $\quad$ Capability Assessment, UGV Operational Modes

- Roadmap for a new UGV solution able to demonstrate the concepts by a preliminary virtual and physical prototype, setting a pilot project and proceeding in the Development Preliminary Analysis on costs and times to put the new UGV system into operations

- $\quad$ Risk Reduction \& UGV Advantages and Criticalities

- $\quad$ Summary of Overall Benefits, Open Issues and Gaps

The authors have been involved in these studies to develop a simulator used to test the possibility of the UGV in dangerous industrial environment in which it has to operate, even in early phases, virtually. 


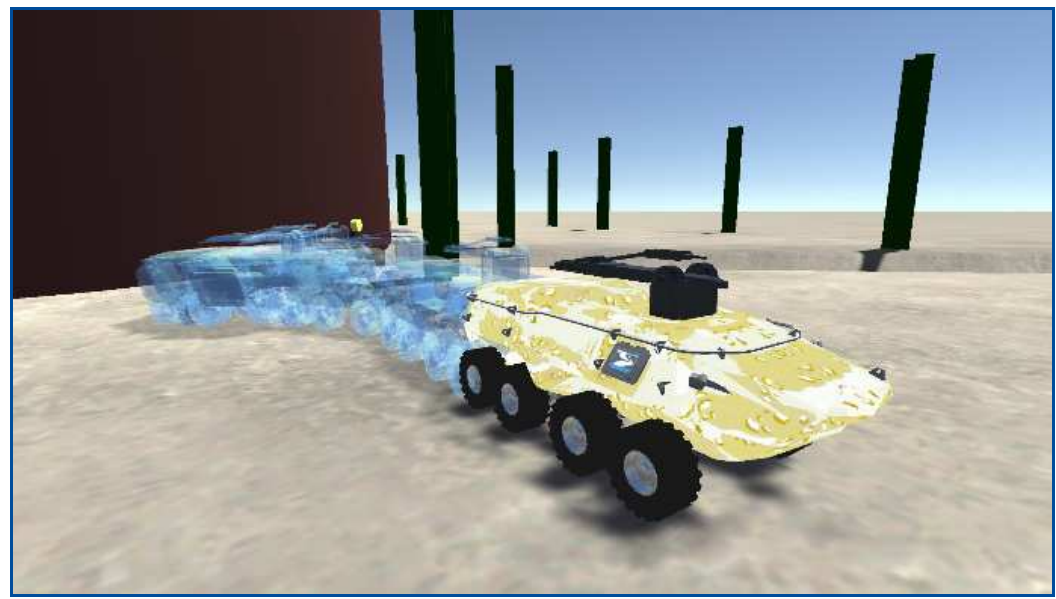

Figure 5 - UGV performing indoor virtual operations

Furthermore the research led to the identification of the main autonomous platform characteristics and the expected degree of autonomy to face industrial plant challenges. The simulator gives good benefit to the research, indeed thanks to it, it has been possible identify multiple aspects such as the effective maximum dimension for the UGV, the degree of Freedom for the arm of the UGV for performing the tasks assigned to him, the possible configurations of his equipment etc..

The research is expected to provide a guideline and roadmap for future development of such UGV solution for creating an industrial UGV.

\section{CONCLUSIONS}

The example propose examples interesting for the potential use of UxVs within Industrial Plants and Processes in order to increase safety. Indeed it is evident that many other different cases are possible and only a few parts of them has been already investigated. The possibilities for using $\mathrm{UxVs}$ are so many that it is very challenging to even list them all and it should expect a large development of these applications in near future.

Therefore, it's evident that the best promising technique able to test a large number of complex scenario in a fast way is $M \& S$ that is expected to become crucial for supporting the diffusion of UxVs in Industry. The virtual environment is also the ideal approach to test the IA and AI solutions to be used to enable collaborative missions and autonomy of these new robotic systems. From this point of view the authors are working with other research team to find solutions that could be flexible enough to be applicable in different industrial sectors

\section{REFERENCES}


1. Altawy, R., \& Youssef, A. M. (2016) "Security, Privacy, and Safety Aspects of Civilian Drones: A Survey" ACM Transactions on Cyber-Physical Systems, 1(2), 7

2. Apvrille, L., Roudier, Y., \& Tanzi, T. J. (2015) "Autonomous drones for disasters management: Safety and security verifications", Proc. 1st IEEE URSI Atlantic, May

3. Bass, T. (2000) "Intrusion detection systems and multisensor data fusion" Communications of the ACM, 43(4), pp.99-105

4. Bruzzone A. G., Massei M., Agresta M., Di Matteo R., Sinelshchikov K., Longo F, Nicoletti L, Di Donato L, Tomassini L., Console C., Ferraro A., Pirozzi M., Puri D., Vita L, Cassandra F, Mennuti C, Augugliaro G., Delle Site C., Di Palo F, Bragatto P. (2017) “Autonomous Systems \& Safety Issues: The Roadmap to Enable New Advances in Industrial Applications", Proc of I3M, Barcellona, Spain, September

5. Bruzzone A.G. (2017) "Information security: threats and opportunities in a safegurading perspective", Lectio Magistralis as Keynote Speech at World Engineering Forum, Rome, November

6. Bruzzone A.G., Longo F., Massei M., Nicoletti L., Agresta M., Di Matteo R., Maglione G.L., Murino G., Antonio Padovano A. (2016a) "Disasters and Emergency Management in Chemical and Industrial Plants: Drones simulation for education \& training”, Proc. of MESAS, Rome, June 15-16

7. Bruzzone A.G., Massei M., Longo F., Cayirci E., di Bella P., Maglione G.L., Di Matteo R. (2016b) "Simulation Models for Hybrid Warfare and Population Simulation", Proc. of NATO Symposium on Ready for the Predictable, Prepared for the Unexpected, M\&S for Collective Defence in Hybrid Environments and Hybrid Conflicts, Bucharest, Romania, October $17-21$

8. Bruzzone A.G., Massei M., Maglione G.L., Di Matteo R., Franzinetti G. (2016c) "Simulation of Manned \& Autonomous Systems for Critical Infrastructure Protection", Proc. of I3M, Larnaca, Cyprus, September

9. Bruzzone A.G., Massei M., Agresta M., Poggi S., Camponeschi F., Camponesch M. (2014) "Addressing Strategic Challenges on Mega Cities through MS2G", Proceedings of MAS, Bordeaux, France, September 12-14

10.Bruzzone, A.G., Berni, A., Fontaine, J.G., Cignoni, A., Massei, M., Tremori, A., Dallorto, M., Ferrando, A. (2013) "Virtual Framework for Testing/Experiencing Potential of Collaborative Autonomous Systems", Proc. of I/ITSEC, Orlando. FL USA

11.Bürkle, A., Segor, F., Kollmann, M. (2011). "Towards autonomous micro uav swarms". Journal of intelligent \& robotic systems, 61(1-4), pp. 339-353.

12.Cárdenas, A. A., Amin, S., Lin, Z. S., Huang, Y. L., Huang, C. Y., \& Sastry, S. (2011) "Attacks against process control systems: risk assessment, detection, and response", Proceedings of the 6th ACM Symposium on Information, Computer and Communications Security, March, pp.355-366

13.Clarke, R., \& Moses, L. B. (2014) "The Regulation of Civilian Drones' Impacts on Public Safety" Computer Law \& Security Review, 30(3), 263-285

14.Di Donato (2017) "Intelligent Systems for Safety of Industrial Operators, the Role of Machines \& Equipment Laboratories", SISOM Workshop, Rome

15.Djellal, F., \& Gallouj, F. (1999) "Services and the search for relevant innovation indicators: a review of national and international surveys", Science and Public Policy, 26(4), pp. 218232

16.Doherty, P., \& Rudol, P. (2007) "A UAV search and rescue scenario with human body detection and geolocalization", Proceedings of the Australian Conference on Artificial Intelligence, Vol. 4830, December, pp. 1-13 
17.Feddema, J.T.; Lewis, C.; Schoenwald, D.A., (2002) "Decentralized control of cooperative robotic vehicles: theory and application, "Robotics and Automation, IEEE Transactions on, vol.18, no.5, pp.852,864, Oct

18.Ferrandez J.M., De Lope H., De la Paz, F. (2013) "Social and Collaborative Robotics", International Journal Robotics and Autonomous Systems, 61

19.Floreano, D., \& Wood, R. J. (2015) "Science, technology and the future of small autonomous drones", Nature, 521(7553), 460

20.Gardi, A., Sabatini, R., \& Ramasamy, S. (2016) "Stand-off measurement of industrial air pollutant emissions from unmanned aircraft", Proc. of IEEE International Conference on Unmanned Aircraft Systems, June , pp.1162-1171

21.Grocholsky, B., Keller, J., Kumar, V., Pappas, G., (2006) "Cooperative air and ground surveillance", Robotics \& Automation Magazine, IEEE, vol.13, no.3, Septmber, pp.16-25

22.Ishiki, T., \& Kumon, M. (2014) "A microphone array configuration for an auditory quadrotor helicopter system", Proc. IEEE International Symposium on Safety, Security, and Rescue Robotics, pp. 1-6

23.Jans, W., Nissen, I., Gerdes, F., Sangfelt, E., Solberg, C. E., \& van Walree, P. (2006) "UUV covert acoustic communications- preliminary results of the first sea experiment", in Techniques and technologies for unmanned autonomous underwater vehicles- a dual use view", RTO Workshop SCI-182/RWS-016, Eckernförde, Germany

24.Jones, D. (2005) "Power line inspection-a UAV concept", Proc. of the IEE Forum on Autonomous Systems, Ref. No. 11271, November

25.Kastek, M., Dulski, R., Zyczkowski, M., Szustakowski, M., Trzaskawka, P., Ciurapinski, W., Grelowska G., Gloza I., Milewski S, Listewnik, K. (2012) "Multisensor system for the protection of critical infrastructure of seaport" In Proc. of SPIE, Vol. 8288, May

26.Kehoe, B., Patil, S., Abbeel, P., \& Goldberg, K. (2015) "A survey of research on cloud robotics and automation", IEEE Transactions on automation science and engineering, 12(2), pp.398-409

27.Kim, D. H., Kwon, S. W., Jung, S. W., Park, S., Park, J. W., \& Seo, J. W. (2015) "A Study on Generation of 3D Model and Mesh Image of Excavation Work using UAV", Proceedings of the International Symposium on Automation and Robotics in Construction, Vol. 32, Vilnius, January

28.Kovacevic, M. S., Gavin, K., Oslakovic, I. S., \& Bacic, M. (2016). "A new methodology for assessment of railway infrastructure condition". Transportation research procedia 14, pp. 1930-1939.

29.Leão, D. T., Santos, M. B. G., Mello, M. C. A., \& Morais, S. F. A. (2015) "Consideration of occupational risks in construction confined spaces in a brewery", Occupational Safety \& Hygiene III, 343

30.Magrassi C. (2013) "Education and Training: Delivering Cost Effective Readiness for Tomorrow's Operations",ITEC Keynote Speech, Rome, May

31.Maravall D., J. de Lopea,b, R. Domíngueza, (2013) "Coordination of communication in robot teams by reinforcement learning", Robotics and Autonomous Systems 61, pp.661-666

32.McCurry Justin (2017) "Dying robots and failing hope: Fukushima clean-up falters six years after Tsunami", The Guardian, March 9

33.Merabti, M., Kennedy, M., \& Hurst, W. (2011) "Critical infrastructure protection: A 21 st century challenge", Proc. of IEEE Int.Conf. on Communications and Information Technology, ICCIT, March, pp. 1-6

34.Merwaday, A., \& Guvenc, I. (2015) "UAV assisted heterogeneous networks for public safety communications", Proc. of IEEE Wireless Communications and Networking Conference Workshops, March, pp. 329-334 
35.Mobley, R. K. (2001) "Plant engineer's handbook", Butterworth-Heinemann, Oxford, UK

36.Nano, G., \& Derudi, M. (2013) "A critical analysis of techniques for the reconstruction of workers accidents", Chemical Engineering, 31

37.Palazzi, E., Caviglione, C., Reverberi, A.P., Fabiano, B. (2017) "A short-cut analytical model of hydrocarbon pool fire of different geometries, with enhanced view factor evaluation", Process Safety and Environmental Protection, August

38.Pizzella, L. A. E. (2014) "Contributions to the Configuration of Fleets of Robots for Precision Agriculture", Thesis, Universidad Complutense, Madrid, Spain, May

39.Pulina, G., Canalis, C., Manni, C., Casula, A., Carta, L. A., \& Camarda, I. (2016) "Using a GIS technology to plan an agroforestry sustainable system in Sardinia", Journal of Agricultural Engineering, 47(s1), 23-23.

40.Richards A., J. Bellingham, M. Tillerson, and J. P. (2002) "How: Co-ordination and control of multiple UAVs", Proc. of the AIAA Guidance, Navigation, and Control Conference, Monterey, CA, August

41.Ross, S., D. Jacques, M. Pachter, and J. Raquet, (2006) "A Close Formation Flight Test for Automated Air Refueling," Proceedings of ION GNSS-2006, Fort Worth, TX, Sep

42.Salvini, P. (2017) "Urban robotics: Towards responsible innovations for our cities", Robotics and Autonomous Systems, Elsevier

43.Sanchez-Lopez, J. L., Pestana, J., de la Puente, P., \& Campoy, P. (2016) "A reliable opensource system architecture for the fast designing and prototyping of autonomous multi-uav systems: Simulation and experimentation", Journal of Intelligent \& Robotic Systems, 84(14), pp.779-797

44.Shafer, A.J., Benjamin, M.R., Leonard, J.J., Curcio, J., (2008) "Autonomous cooperation of heterogeneous platforms for sea-based search tasks", Oceans, , September 15-18, pp. 1-10

45.Shkurti, F., Anqi Xu, Meghjani, M., Gamboa Higuera, J.C., Girdhar, Y., Giguere, P., Dey, B.B., Li, J., Kalmbach, A., Prahacs, C., Turgeon, K., Rekleitis, I., Dudek, G., (2012)"Multidomain monitoring of marine environments using a heterogeneous robot team", Proc. of IEEE Intelligent Robots and Systems (IROS), vol., no., pp.1747,1753, October 7-12

46.Siebert, S., \& Teizer, J. (2014) "Mobile 3D mapping for surveying earthwork projects using an Unmanned Aerial Vehicle (UAV) system", Automation in Construction, 41, pp.1-14

47.Spanu S., M. Bertolini, E. Bottani, G. Vignali, L. Di Donato, A. Ferraro, F. Longo (2016) "Feasibility study of an Augmented Reality application to enhance the operators' safety in the usage of a fruit extractor", Proc. FoodOPS, Larnaca, Cyprus, September 26-28

48.Spillane, J. P., Oyedele, L. O., \& Von Meding, J. (2012) "Confined site construction: An empirical analysis of factors impacting health and safety management", Journal of Engineering, Design and Technology, 10(3), pp.397-420

49.Stilwell D. J., A. S. Gadre, C. A. Sylvester and C. J. Cannell (2004) "Design elements of a small low-cost autonomous underwater vehicle for field experiments in multi-vehicle coordination", Proc. of the IEEE/OES Autonomous Underwater Vehicles, June, pp. 1-6

50.Sujit, P. B., Sousa, J., Pereira, F.L., (2009) "UAV and AUVs coordination for ocean exploration", Oceans - EUROPE, vol., no., pp.1,7, 11-14 May

51.Tanner H. G. (2007a) “Switched UAV-UGV cooperation scheme for target detection”, IEEE International Conference on Robotics and Automation, Roma, Italy, April, pp. 3457-3462.

52.Tanner H.G., D.K. Christodoulakis, (2007b) "Decentralized cooperative control of heterogeneous vehicle groups", Robotics and Autonomous Systems 55,pp 811-823

53.Tether, T. (2009) "Darpa Strategic Plan", Technical Report DARPA, May

54.Vail D. \& M. Veloso, (2003) "Dynamic multi-robot coordination", Multi-Robot Systems: From Swarms to Intelligent Automata, Vol II, pp. 87-100. 
55.Valavanis, K. P., \& Vachtsevanos, G. J. (2014) "Handbook of unmanned aerial vehicles", Springer Publishing Company, NYC 